\title{
Design for Supportability: An Essential Component of New Product Development
}

\begin{abstract}
Do you evaluate product support requirements at the design stage? Leading companies do and, what's more, they use this as a lever to gain competitive advantage.
\end{abstract}

\author{
Keith Goffin \\ Cranfield School of Management, Cranfield, \\ Bedford MK43 0AL, England, UK \\ Tel: $0044(0) 1234-751122$ \\ Fax: 0044 (0)1234-751806 \\ email: k.goffin@Cranfield.ac.uk
}

\begin{abstract}
OVERVIEW
During new product development, $R \& D$ engineers need to consider a wide range of often conflicting requirements, including product features, cost, quality and manufacturability. Another factor, which is often neglected by companies, is to ensure that products are easy and economical to service and support-i.e. to install, to maintain, to repair, to operate, etc. Products support is an essential factor for achieving customer satisfaction in many industries, including both high-tech sectors such as computing and low-tech sectors such as domestic appliances. Leading companies recognize both the importance of product support and the significance of evaluating support requirements at the design stage-using Design for Supportability techniques. This enables them to gain competitive advantage from customer support and earn significant revenues.
\end{abstract}

\section{THE AUTHOR}

Keith Goffin is a Senior Lecturer in Operations Management at Cranfield School of Management in the UK. He has a BSc with first-class honours in physics, an MSc in Medical Physics from Aberdeen University in Scotland and $\mathrm{PhD}$ in management from Cranfield. For fourteen years he worked for the Hewlett-Packard Medical Products Group: on new product development; managing customer support groups; and as a marketing manager. In 1995, Keith joined the teaching faculty of Cranfield and his research interests are all in the field of innovation. He has published in a number of international journals and is currently conducting a major research project comparing innovation management in German and UK companies.

\section{INTRODUCTION}

New product development (NPD) engineers typically have a wide range of requirements to consider at the design stage. These include product features, cost, quality, and manufacturability. Since engineering resources are limited and fast time-to-market is essential in today's markets, it is not surprising that another issue-product support—is often neglected during NPD. However, failing to give appropriate attention to product support at the design stage is a missed opportunity. This is because good product support, including installation, customer training, maintenance and repair is essential to achieving customer satisfaction in many markets. In addition, support can be a major source of revenue and can 
bring sustainable competitive advantage. Therefore, it is important for engineers working on new product development to understand:

- The scope and role of product support

- How companies gain a competitive advantage from support

- How product design influences product support

- How to evaluate support requirements at the design stage, using what are called Design for Supportability techniques.

\section{THE SCOPE AND ROLE OF SUPPORT}

Product support, also known as customer support or after-sales support, is the name given to the various forms of assistance that companies offer customers to help them gain maximum value from manufactured products. Typical forms of support include installation; training on a product; maintenance and repair services (generally termed service); documentation; availability of spare parts; upgrades (enhanced functionality); customer consulting; and warranty schemes. Product support plays a key role in the marketing of both high-technology and engineering products. For example, both car owners and personal computer owners expect prompt and efficient service. Similarly, organizations using computer systems or communication networks can only obtain maximum value from their equipment when good support is available to help them understand the full capabilities of their equipment and keep it running without interruption.

Recognition of the importance of support to businesses has grown over the last ten years. Support used to be thought of as just service (mainly product maintenance and repair), a backwater not worthy of management attention. However, the scope of product support has broadened to include such aspects as upgrades and user training (see Figure 1), and attitudes are now changing. What has changed to increase management recognition of support? Three key factors can be identified:-

1) For many products, support plays a key role in ensuring customer satisfaction and it has a strong influence over whether customers will purchase again. For example, surveys published in trade journals from the car industry, domestic appliances, aircraft and computing all regularly identify support as playing a key role.

2) Support can be a major source of revenue. In addition, it can be very profitable area-with margins exceeding those made on the products themselves. A recent McKinsey study concluded that "in most industrial companies, the after-sales business accounts for 10 to 20 percent of revenues and a much larger portion of total contribution margin" [1].

3) New technologies are changing many aspects of support. For example, today's products are more reliable and this has reduced the relative importance of maintenance and repair. On the other hand, the complexity of equipment has often increased, particularly if it is software-based. This has raised the relative importance of aspects of product support such as user training and telephone support. Consequently, designers need to consider how they can make support easier because of the costs involved-for example software support costs are typically $6 \%$ of revenues in the software industry [2].

\section{INSERT FIGURE 1}

"in most industrial sectors, the after-sales business accounts for 10 to 20 percent of revenues..." McKinsey study 


\section{COMPETITIVE ADVANTAGE THROUGH SUPPORT}

Leading companies use product support for achieving competitive advantage. For example, the Caterpillar corporation's support of their earth-moving equipment is legendary-guaranteed delivery of spare parts anywhere in the world within 48 hours and machines which can be repaired quickly and economically (for more details see [3]). In sectors where it may be difficult to differentiate through product features alone, support can give strong leverage. Competitive advantage can either come from a well-trained field organization or from products which have been specifically designed for efficient support [4]. However, it is when these two approaches are combined that a long-term advantage can be achieved. Consider the following three examples:

\section{Kodak in the Photocopier Market.}

Modern photocopiers offer far more than just copying functions. Some are moving in the direction of desk-top publishing systems and offer formatting, binding and other capabilities. However, many of these functions are not used on a daily basis in an office environment. What does this mean to the office employee who urgently needs a special format document copied and bound for a sales training tomorrow? Has this person time to sit and read the manual? Of course not, but companies such as Kodak have already recognized this and are offering extra services. Their copiers can be connected to response centers by modem and they can, in telephone conversations with the user, determine the format required, set the copier controls remotely and produce the first copy for review. The user can then give his comments or ideas for improvements, settings can be changed remotely and bulk copying can begin.

Kodak focuses on Design for Supportability and the modem connections were originally designed for remote maintenance purposes. However, Kodak have managed to create a good link between a technical feature and an extra service for customers. This example shows that investments made primarily for support reasons can also have direct applications for helping customers.

\section{Hewlett-Packard in Medical Ultrasound}

Medical ultrasound has many applications, with diagnosis of cardiovascular disease being one of the most important. Hewlett-Packard (HP) entered this market in the 1980s with a system designed for upgradability. Nearly twenty years later, this philosophy is still central to HP's marketing of medical ultrasound.

In hospitals, the working lifetime of ultrasound equipment is about seven years. However, rapid technological advances in this market mean that significant improvements are made in equipment performance every year. Since many hospitals do not have the funding to buy new equipment annually, the capability to upgrade is very important. Many ultrasound companies have re-purchased old equipment in trade-in programs. Sometimes this old equipment has been refurbished and upgraded in the factory. However, the HP product was the first designed for field upgradabiltiy. On one product, a total of over 25 new revisions have been offered to customers (including both hardware and software changes). Each time, existing customers have had the opportunity to purchase upgrades for their machines, to keep them at the leading edge of technology.

\section{VendorC in the Vending Machine Market}

VendorC is a pseudonym for a company which designs, manufactures, sells and supports complex vending machines-it is a significant market player. Vending companies buy large numbers of 
machines to provide self-service sales of a wide range of goods, some of high value. Modern vending machines-often referred to as vending terminals - are a complex mix of mechanical, electronic, security and display technologies and a top range model can cost in the region of $\$ 15,000$. Due to the large number of mechanical components in vending machines and their high levels of usage, regular maintenance and repair is required. Vendor terminals can now be linked via modems to a central computer, which remotely monitors performance, sales activity and stock levels in chains of vending machines. Using modem links, VendorC offer full goods management to their customers i.e. ensuring that machines are both efficiently maintained and replenished with sales goods in a timely fashion. This incremental service is a new and important source of revenue for VendorC and arose from their consideration of support needs at the design stage.

Management at VendorC assigns significant resources to Design for Supportability because product support is an essential part of their business. Support generates 35\% of sales at margins of typically $25 \%$ and customer support is the source of competitive advantage-so much so that the company does not want to draw their competitors' attention to product support and consequently wants to remain anonymous.

\section{HOW DESIGN INFLUENCES PRODUCT SUPPORT}

How does product design influence product support? Design influences both the amount of support necessary and the way it can be delivered [5]. Decisions taken at the design stage affect product reliability and consequently how often products require maintenance [6]. Similarly, modular design can reduce repair costs and fault-finding is made easier by good diagnostics. In addition to repair and maintenance, design also influences user training and upgradability. Therefore "design characteristics such as... supportability have a great impact on both the effectiveness and cost aspects of the system" [7]. For example, remote support may avoid the need for expensive on-site visits by field support engineers and on-board computer based training (CBT) can significantly reduce the amount of direct training that users require on complex products.

A good analogy to the need to evaluate support at the design stage is the need to consider manufacturing requirements. Design for Manufacturability (DFM), which was developed in the 1980s, evaluates manufacturing requirements at the design stage, enabling the development of products which are easy and cost-effective to produce. DFM stresses that seemingly insignificant decisions made during the initial design phase will affect manufacturing throughout the product's life cycle and, if considered early enough, most products can be designed for easy manufacture. DFM has played a strong role in manufacturing and one study concluded that it "can play a major role in reducing costs and increasing productivity" [8]. The success of DFM has led to the realization that something similar is required to ensure that support issues are fully considered during NPD [9][10]. However, support requirements typically do not receive enough attention during new product development.

\section{SUPPORT AND NEW PRODUCT DEVELOPMENT}

Several factors typically prevent companies from developing products with high supportability i.e. products which are easy and efficient to support. These are:-

- Support requirements are considered too late in the product development cycle.

- Field support engineers and managers, who know support problems first-hand, do not have the opportunity to influence product designs.

- Decisions taken to lower production costs may make support more difficult or more expensive.

- Product features often take priority over product support considerations. 
Several studies have found that support is often neglected during NPD. One found that only $40 \%$ of companies "fully" considered service requirements at the design stage [11]. Another survey, conducted by the author, showed that many high-technology companies do not consider support until well into the product development cycle — on average after two-thirds of the development cycle has passed. At this stage, it is probably too late to ensure high supportability of product, because many key design decisions have already been taken. With faster time-to-market becoming the norm, it is even more important for product support to be considered right from the beginning.

In most cases $R \& D$ engineers do not have up-to-date knowledge of the issues facing field support personnel and so are not qualified to evaluate support issues on their own. However, field support engineers who know the issues first hand are seldom consulted on the suitability of proposed designs; research in the US has revealed that field personnel are only "occasionally involved in new product work" [12]. Leading companies such as NCR, HP, GE and AT\&T have recognized the importance of using panels of field experts to review the supportability of new designs at the concept stage [13]. All aspects of product support should be considered (as illustrated by Figure 1), whereas research has shown that many companies limit their evaluation at the design stage to repair and maintenance issues only, thus omitting many key aspects [14][15]. The evaluation of all aspects of product support at the design stage is called Design for Supportability (DFS).

If companies are not careful, decisions taken to lower production costs may increase support costs. An example is memory boards for firmware-based products. The goal of minimum material costs often leads production personnel to choose non-reprogrammable memory chips for equipment firmware. However, when products need to be field upgraded, this can increase costs-as whole memory boards need to be exchanged. The author knows of two major international companies where this was the case- $\mathrm{a}$ few dollars were saved in production but the costs of field upgrades were enormous when the companies had to upgrade their installed base (to solve software problems). It is essential that both development and production engineers consider all of the costs associated with the use of a product over its working lifetime-cost-of-ownership. This is because higher development and production costs can sometimes lead to lower lifetime costs! Comprehensive approaches to planning the lifetime costs of products combine DFS with other considerations such as Design for Recycling (which is becoming ever more important [16]) and Design for Logistics (designing products and packaging for safe, efficient and economical distribution).

A major reason why Design for Supportability is often neglected is that R\&D engineers tend to give product features a higher priority, as these may be more interesting to develop. In addition, product managers may forget the importance of support and the associated revenues. This is particularly common at companies where product-development entities are a separate organization from the field organization which supports released products. In this case, the field organization's revenues are separate from the manufacturing division's and so there is little financial motivation for the latter to develop products which are easier and more profitable to support. This is because implementing DFS may require significant investments for which no return will be seen in the product-development entity's bottom line. However, leading companies evaluate the return on investment from product features and compare this to how investments in supportability can give returns over the working lifetime of the product. Many product "bells and whistles" are better replaced by functions to make products easier to support.

"bells and whistles" are better replaced by functions which make products easier to support.

\section{DESIGN FOR SUPPORTABILITY}


Some companies excel at developing products with high supportability; Rank Xerox, Hewlett-Packard and VendorC for example. They achieve this through an excellent understanding of customer needs and an evaluation of product support early in the design cycle.

Rank Xerox was one of the first companies to fully evaluate support requirements at the design stage. They are particularly strong at surveying customers' support needs-something that many companies forget by conducting market research that investigates product features only. Rank-Xerox also set goals for all aspects of support at the design stage; an example is their analysis of the access time to various modules of a photocopier. They found that more money was saved by considering field repair times than was saved by DFM methods speeding up assembly time in production. Why? The reason was simple. A copier is assembled once in the factory but repaired in the field (including disassembly and re-assembly) several times during its working lifetime by field engineers. Rank-Xerox now have a company design goal that the field access time to any component/module in a photocopier must be less than five minutes.

VendorC, the vending machine company, excels at Design for Supportability. Their new products typically require 18 months development and the team working on NPD includes R\&D, product management, manufacturing, suppliers and product support specialists from the start. Over the last five years, a strong focus on product support by top management has led to the consideration of service issues being "pushed further back into the design" [VendorC executive] and becoming an integral part of NPD. At the design stage product support specialists analyze the RASUI of productsthe reliability; availability; serviceability; usability; and installability. For each of these five categories a detailed analysis is performed and design recommendations are made. Modular design, for quick replacement of faulty or worn components is standard practice and extensive diagnostic capabilities are developed for each product. The Quality Department has the responsibility to take a particularly critical look at whether RASUI goals are met during NPD. VendorC's focus on customer support and DFS has enabled them to use it to gain a significant competitive advantage. They offer a combination of reliable, highly-functional products and a responsive field organization which is unique in their industry and, significantly, have seen extremely high returns on their investments in DFS.

\section{...research shows that companies typically go through five major stages in the progression towards full Design for Supportability}

Hewlett-Packard has always had a strong reputation for good product support and have focused on DFS since the early 1990s. Two key elements in their approach to DFS are their lifetime costs model approach and their financial reporting. To identify the issues and costs involved with support, a lifetime model is used and Figure 2 shows an example for a medical electronics product. The diagram illustrates the "events" during the working lifetime of a product, from installation, through use and maintenance to removal from service. By determining the frequency of each event (for example installation normally only takes place once but a product may require several upgrades over its lifetime) and the associated costs, better decisions can be taken about the potential returns on investments in making support more efficient. This is particularly important as certain aspects of support are covered by warranty, whereas others such as upgrades generate revenue for HP. Therefore, the lifetime model ensures that all aspects of support are considered at the design stage and not just repair and maintenance (more details of HP's approach can be found in [17]). As mentioned earlier, supportability issues may have to "compete" for resources during NPD with product features or manufacturability. Therefore, a clear understanding of the cost implications of support is essential and the lifetime cost model helps. However, HewlettPackard have gone further and changed their financial reporting so that product divisions (which design and manufacture products) see financial returns on their DFS investments. Previously, all field support 
revenues had been reported separately and so the motivation in the product divisions to invest heavily in DFS was low (because these investments would make the field support organization more efficient but not increase factory margins). Following the change in financial reporting, better investment decisions have been made during NPD.

INSERT FIGURE 2

In addition to the three examples mentioned, extensive research by the author in a range of industries shows that companies typically go through five stages in the progression towards full Design for Supportability, as illustrated by Figure 3. Companies at Stage 1 do not recognize the potential of support business. Consequently, they do not evaluate support at the design stage. Symptomatic of companies at Stage 1 is the customer support organization having a low status and field support complaining about product designs. Poor product design means higher repair costs and can lead to dissatisfied customers. Therefore, failing to consider product support at the design stage often has a negative business impact, as indicated by the position of Stage 1 on the diagram.

At Stage 2, companies consider reliability and repair times at the design stage and typically set quantitative goals for product reliability (mean-time-between-failures, MTBF) and ease-of-repair (mean-time-to-repair, MTTR). However, broader aspects of support are not considered at the design stage. Further progression leads to Stage 3, where companies involve panels of field engineers in NPD reviews. However, field engineers' ideas and suggestions often cannot be implemented because these reviews come too late in the development cycle. Therefore, it is essential to evaluate all aspects of support at the design stage i.e. installation times; fault diagnosis times; field access times; repair times/costs, user training times; upgrade times; etc. Implementing this effectively into the NPD process is difficult and it often takes companies a long time to reach Stage 4. At Stage 4 companies approach design for supportability in a similar way to DFM-i.e. they set quantitative goals at the design stage for all aspects of support. These goals push development engineers to develop designs which are easier and more profitable to support than previous products. Cost models are used to guide the decisions which may need to be made about trade-offs between features, manufacturability and supportability.

Some leading companies have reached Stage 5, which is characterized by all of the issues considered at Stage 4 with two important additions. Firstly, financial reporting mechanisms are used to ensure that return on DFS investment is clearly visible to management. Secondly, and fundamentally, companies which reach Stage 5 have management teams which fully recognize the importance of support revenues to their businesses and consequently devote sufficient management resources to identifying incremental services which can further increase support revenues. Achieving this change in attitude is something many companies find hard.

\section{INSERT FIGURE 3}

Few companies have reached Stage 5, as shown by survey results on 66 high-technology companies [17]. Prevoius research has identified examples of the importance of evaluating support requirements at the design stage at several companies [4]. However, new case study research looking at the five market leaders in five different industries indicates that leading companies are obtaining a significant competitive advantage from product support and this has contributed to their achievement of top market shares [18]. In addition, the companies which are most advanced at DFS appear to be earning higher revenues from customer support than their competitors. DFS investments can bring significant returns in any industry where support plays an important role but successful companies are normally reluctant to divulge exact figures on the increased revenues or higher profits which result. 
However, the case of VendorC discussed earlier shows that DFS can lead companies to discover new services for their customers and significantly increase revenues. In addition, the advantages of DFS can be illustrated by the following two examples.

Small passenger aircraft is a competitive sector in which margins are low and the cost of materials and vendor components can often exceed $65 \%$ of sales. The main purchasing criterion for airlines is the dollars per passenger mile i.e. the revenue they can expect per passenger per mile flown. A major factor which influences dollars per passenger mile is the cost of aircraft maintenance and aircrew training. Consequently, companies in this market have focused on DFS for some years. However, leading companies are now concentrating on ensuring that their suppliers understand the importance of reducing maintenance costs and actively contribute to this by designing components with the support requirements of the complete aircraft in mind. In demanding markets, DFS can be an important issue to discuss with suppliers, as it can have a direct impact on the competitiveness of the finished product.

An example of the advantage of evaluating repair issues at the design stage comes from the car industry. Leading car manufacturers consider all aspects of product support at the design stage, including damageability issues i.e. the probability of each part of a car being damaged in an accident and the cost of the necessary repair. This is important because car insurance companies closely monitor the costs of repairing accident damage and use it in their determination of which insurance category applies to a particular model of car. Therefore, repair costs have a direct influence on the cost of insurance-which itself has a major impact on product sales. Since Volkswagen have recognized this, they conduct a full evaluation at the design stage of potential accident damage and consequently have reduced the cost of insuring the latest model of their Golf. To minimize repair costs, the Golf has bolton (instead of welded) panels, and fenders that are moulded in three separate parts which allows partial replacements. The low insurance costs have given Volkswagen a competitive advantage and has forced some of their competitors to make expensive changes in the design of their existing products.

\section{SUMMARY}

Product support is a key source of revenue and a means for competitive advantage in many industries. However, to gain the full advantage from support, manufacturing companies need to fully evaluate customer support requirements at the design stage because they are strongly influenced by product design. Consequently, R\&D engineers need to be aware of the scope and importance of support and field support representatives need to be members of NPD teams. When conflicts arise during NPD, between support and other requirements (e.g. manufacturability), informed decisions need to be made by using lifetime cost models. These models need to take account of all Design for $x$ Factors (DFM; DFS; Design for Logistics, Recycling, etc.) and balance them with NPD goals. Research has shown that companies typically progress through five stages before full DFS implementation is achieved and this transition can take years. Although achieving efficient Design for Supportability takes time because attitudes may need to be changed, the rewards for companies which achieve best practice in this area are significant—higher and more profitable support revenues.

\section{REFERENCES}

[1] Knecht, T., Leszinski, R. and Weber, F.A. "Making Profits After the Sale". The McKinsey Quarterly 1993, No. 4, pp79-86.

[2] Blaisdel, M. "Support Enters the Twentieth Century". Info World, 12(41), October 8 1990, pp5962.

[3] Fites, D. V. "Make Your Dealers Your Partners". Harvard Business Review, March-April 1996, pp40-51. 
[4] Goffin, K. "Gaining a Competitive Advantage from Support: Five Case Studies". European Services Industry, 1(4), December 1994, pp1, 5-7.

[5] Garvin, D.A. Managing Quality. New York: The Free Press, 1988.

[6] Lele, M.M. "How Service Needs Influence Product Strategy". Sloan Management Review, 28(1), Fall 1986, pp63-70.

[7] Blanchard, B.S. "The Impact of Integrated Logistic Support on the Total Cost-Effectiveness of a System”. International Journal of Physical Distribution \& Logistics Management, 21(5), 1991, pp23-26.

[8] Boothroyd, G. and Dewhurst, P. "Product Design for Manufacture and Assembly". Manufacturing Engineering, 100(4), April 1988, pp42-46.

[9] Berg, J. and Loeb, J. "The Role of Field Service in New Product Development and Introduction". AFSM International-The Professional Journal, 14(9), May 1990, pp25-30.

[10] Teresko, J. "Service Now a Design Element". Industry Week 243(3), February 1994, pp51-52.

[11] Clark, G. After Sales Service in UK Manufacturing. Cranfield School of Management, UK, Working Paper, April 1988.

[12] Page, A.L. "Assessing New Product development Practices and Performance: Establishing Crucial Norms". Journal of Product Innovation Management, 10(4), September 1993, pp273-290.

[13] Hull, D.L. and Cox, J.F. "The Field Service Function in the Electronics Industry: Providing a Link between Customers and Production/ Marketing". International Journal of Production Economics, 37(1), November 1994, pp115-126.

[14] Goffin, K. "Design for Support: Results of a UK Survey". AFSM International - The Professional Journal, 14(10), July 1990, pp24-29.

[15] Griffin, A., Gleason, G., Preiss, R. and Shevenaugh, D. "Best Practice for Customer Satisfaction in Manufacturing Firms”. Sloan Management Review, 36(2), Winter 1995, pp87-98.

[16] Parker, K. "Being Green Doesn't Have to Hurt". Manufacturing Systems 11(10), October 1993, pp31-36.

[17] Goffin, K. "Evaluating Customer Support during New Product Development-An Exploratory Study". Journal of Product Innovation Management, 15(1), January 1998, pp42-56.

[18] Goffin, K. "Customer Support Distribution Channels: Five Exploratory Case Studies". Cranfield School of Management Working Paper, 1998. 
Figure 1: Product Support has changed significantly in many industries over the last ten years. It used to consist mainly of maintenance and repair issues but now also includes a wide range of elements such as telephone support and customer consulting.

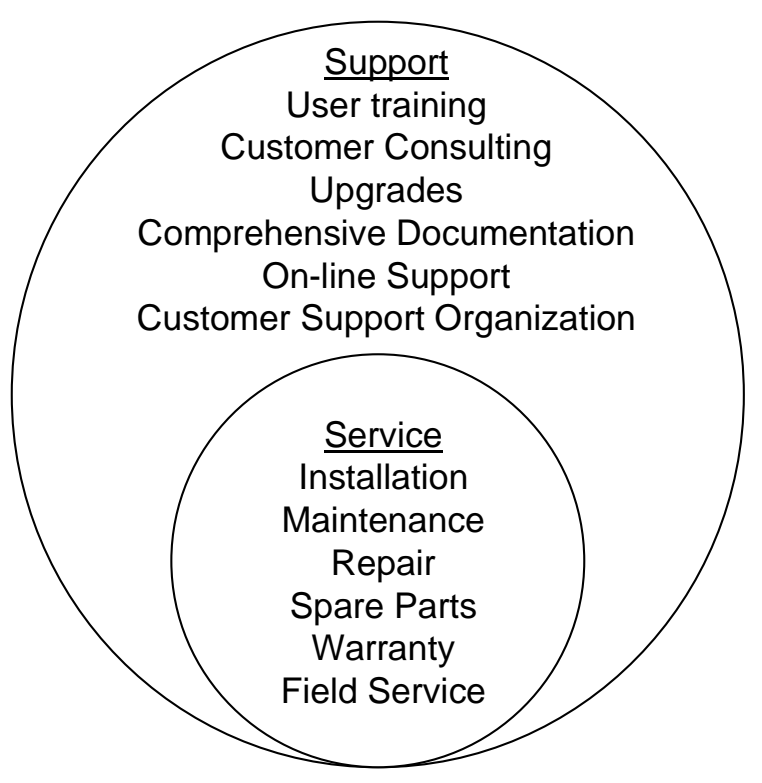


Figure 2: Making the right design choices requires a detailed analysis of lifetime costs. HewlettPackard use a flow diagram to analyze both the frequency and associated costs of all support "events" (such as installation or upgrading) over the working lifetime of the product.

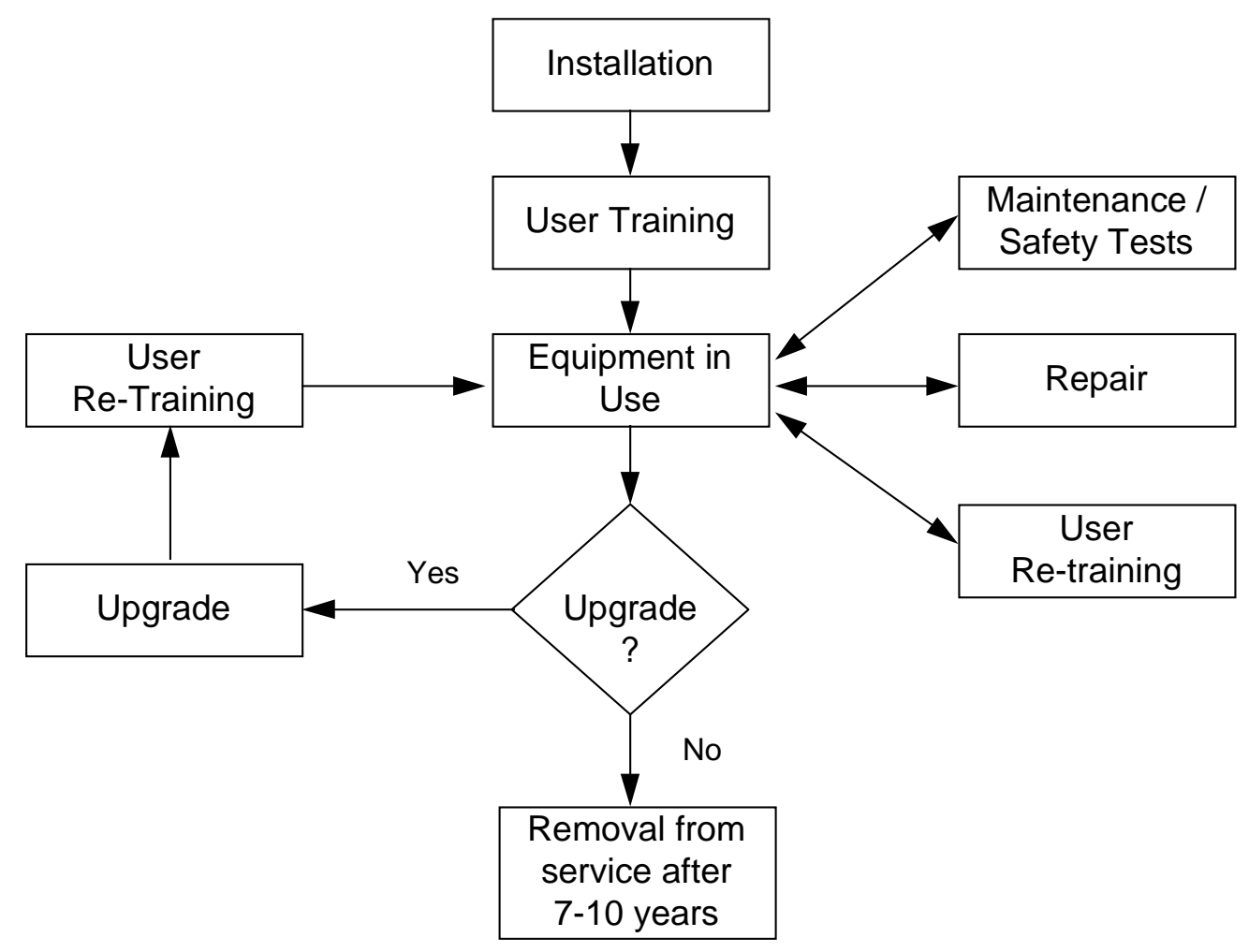


Figure 3: Typically companies move through a number of stages from when they recognize the importance of product support until when they achieve effective Design for Supportability (based on research conducted by Cranfield School of Management).

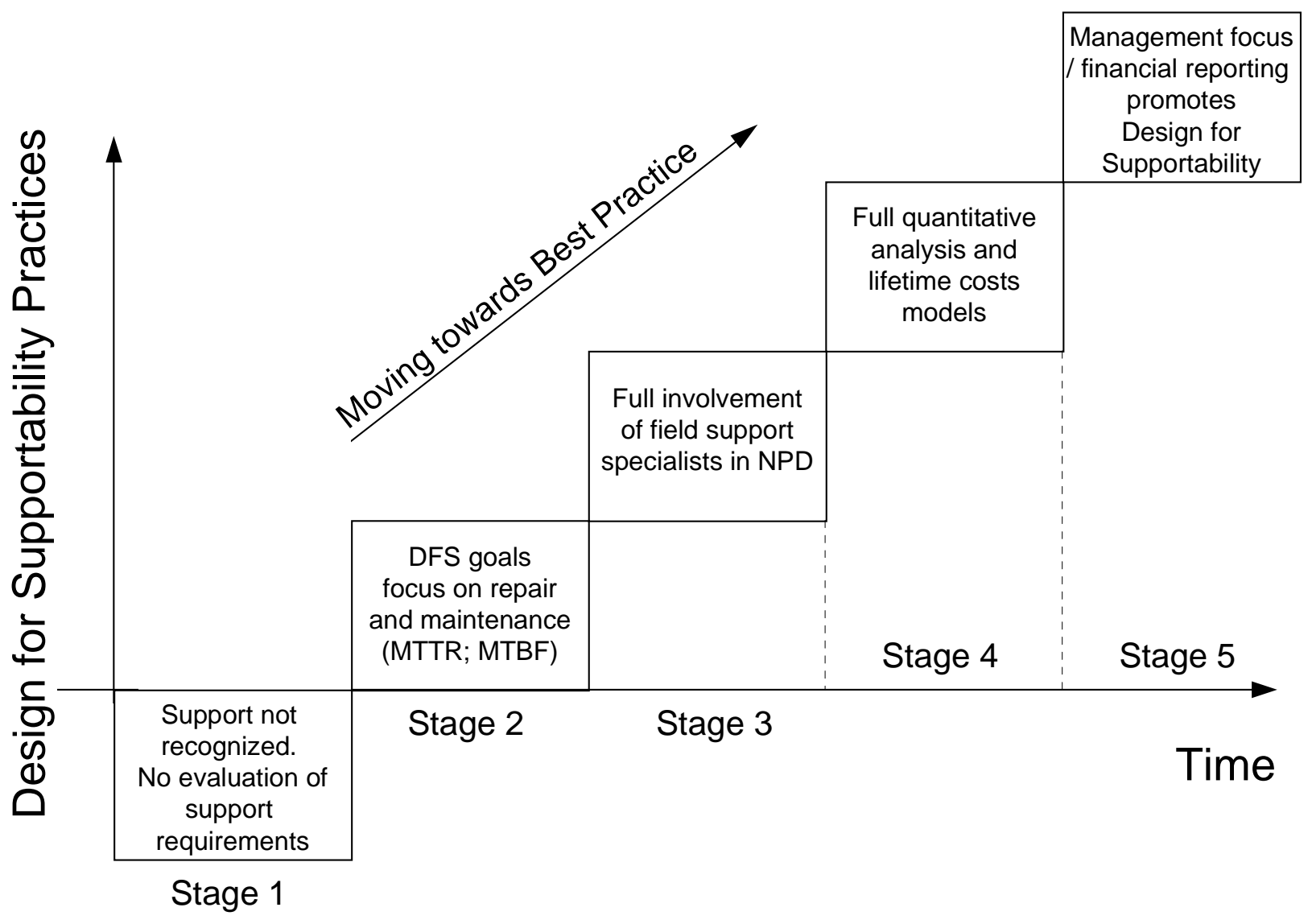

